\section{GMAG wants to stay on}

BRITAIN's representative and gentlemanly Genetic Manipulation Advisory Group wishes to be prolonged for a further term. The 19-member GMAG, established in December 1976 and containing 8 members appointed as scientific and medical experts, 5 able to represent the public interest, 4 nominated by the Trades Union Council to represent the interests of employees, and 2 to represent the interests of management, had by February 1978 provided advice on the control of potential hazards from over 100 recombinant DNA experiments. Last week it published its first annual report.

GMAG bears no legal liability for the advice it offers, its recommendations have no direct statutory force, and-unlike the National Institutes of Health in the US-it has no sanction of withholding grants to stimulate researchers to follow its guidelines. It survives in the UK under the broad umbrella of the Health and Safety at Work Act, which puts an obligation on employers to follow the best advice available to maintain the welfare of their employees.

In its 18 months, GMAG has had notification of 236 workers involved in recombinant DNA research, and received 102 proposals for experiments from 27 centres. GMAG has placed 31 of the experiments under category $I$ of the Williams containment guidelines, 40 under category II, 27 under category III, and 4 under category IV. The levels, says GMAG in its report, range from "good microbiological laboratory practice (at level I) to practice appropriate for the handling of the most dangerous pathogens (at level IV)".

The category IV experiments involve: random nucleic acid from mammals (or birds) in an undisabled vector-host system (1 proposal); random nucleic acid from viruses pathogenic to man in a disabled system ( 2 proposals); and an experiment on infectivity in animals in which the containment is necessary to keep out other infections, not to contain the experimental material.

GMAG members inspected the only potential category IV containment facility in Britain-at Porton Down Microbiological Research Establishment near Salisbury last Friday and, according to its director, Dr R. J. C. Harris, gave it a clean bill of health. Dr Harris expects to receive GMAG's letter of approval this week. If it is forthcoming Dr Harris believes experiments at level IV could begin at Porton in July.

Seven laboratories have been approved for category III experiments: two in London (Imperial Colleg a and the Imperial Cancer Research Fund Laboratory), and others in Edinburgh, Glasgow, Porton, and in industry (G. D. Searle and Co Ltd at High Wycombe and ICI at Runcorn).

GMAG seems to be pleased with the speed with which it undertook the task allocated to it. It responded with definitive advice to the majority of proposals within 5 weeks of receipt. "The scientific community showed great public spirit in holding off an exciting field of research" says the report. "Any further delay... seemed likely to destroy [its] willingness to co-operate". Despite its haste, GMAG has experienced some resistance to its operations. In training biochemists and molecular biologists in the necessary microbiological safety techniques the group found that "even for very bright molecular biologists correct procedures are not instinctive". More disturbingly, they add "a small minority have made clear their disregard for these procedures".

The group offer a warning to the delinquent minority: "however strong an individual worker's intuitive feeling may be that the hazards have been greatly overestimated, we--and the public generally-have a right to expect of him, until we know more of the reality of the situation, that he should do the work either with scrupulous care or not at all".

GMAG nevertheless recognises the broad agneement in the field that the dangers were overestimated. "A substantial amount of recent work suggest that there is negligible risk of the laboratory strains of $E$. coli becoming converted into endemic pathogens or established in the alimentary canal" says the report. "If those findings stand up to careful scrutiny it will appear that many of the more extravagant predictions of risk can be disregarded".

However such a view rests as much upon feeling as on fact. The experiments which are commonly quoted as indicating that 'genetic engineering' goes on in nature as well as in the lab were undertaken in highly artificial conditions (cells doped with massive amounts of the necessary enzymes). And it appears that very recent work undertaken by Dr Harris at Porton indicates that the 'disabled' X 1766 strain of $E$. coli, the basis of the only $\mathrm{NIH}$ severely disabled (EK2) system, can be bred in a form which survives in the gut--so it may not be so disabled after all. It therefore follows that the continued scrutiny the report calls for, and the continued existence of GMAG, are necessary.

Robert Walgate

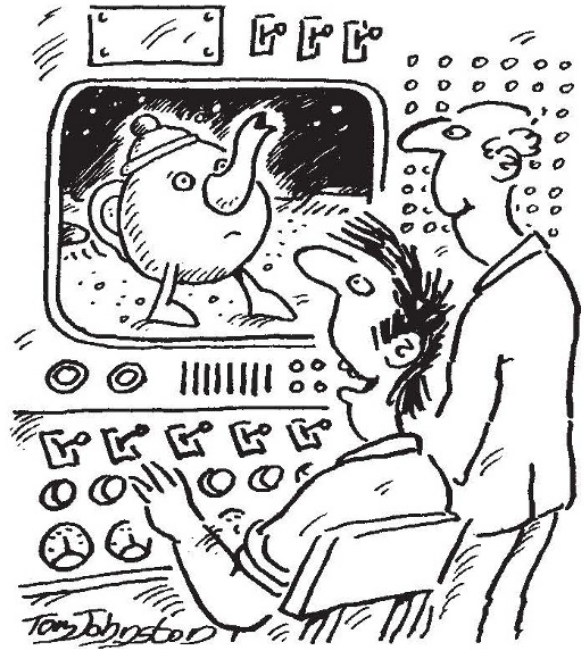

"I think Venus is going to be our kind of planet!"

\section{Britain's giant leap to Venus}

A PIECE of Britain left the Earth for Venus last week. "To the best of my knowledge", says Professor Houghton of Oxford University "it is the only piece of British hardware to leave the Earth's gravitational field". It went up on board the first of two missions to Venus, recently launched by the US National Aeronautics and Space Administration.

When the spacecraft reaches the planet in December, it will go into orbit and take measurements on the Venusian atmosphere. The pioneering piece of British hardware, a pressure modulator radiometer developed and built at Oxford, will be used by a joint US/British team to measure the temperature of the upper atmosphere and the distribution and structure of the higher clouds.

The second mission, scheduled for launch in August, is planned to arrive at Venus only six days after the orbiter. It will send several probes into the atmosphere to investigate the cloud content, the amount of radiation penetrating the upper atmosphere, and the nature of the Venusian surface.

\section{Space shuttle debut officially postponed}

THE US National Aeronautics and Space Administration announced last week that the target date for the first orbital flight of the space shuttle has officially been changed from March to June of 1979 , primarily because of problems encountered in the development of the vehicle's main engines. 